\title{
RANCANG BANGUN PROTOTIPE ALARM PENGINGAT WAKTU KULIAH BERBASIS MIKROKONTROLLER ARDUINO MEGA DI RUANG UNIT KEGIATAN MAHASISWA
}

\author{
${ }^{1}$ Gesang Raharjo, ${ }^{2}$ Mochammad Djaohar, ${ }^{3}$ Aris Sunawar \\ 1,2,3Pendidikan Teknik Elektro, Fakultas Teknik, Universitas Negeri Jakarta \\ 1,2,3 Email: gesang@gmail.com ; djaohar@unj.ac.id ; arissunawar@unj.ac.id
}

\begin{abstract}
The purpose of this study is to create a public alarm to reduce the number of active student delays in class while in the BPRS ERA-FM UNJ secretariat by personally mentioning students who have lecture time, reminders when students forget when they are broadcasting, talking or making other assignments, because the BPRS ERA-FM UNJ is a student activity unit that has a busy day which is broadcast itself. As well as the security of the secretariat by using a card as a substitute for conventional keys to reduce the loss of secretariat items, and the use of a more tidy outlet. Mega Arduino as the main microcontroller controls the alarm system and secretariat security. This tool uses electricity from PLN.

This research uses research and development methods which include needs analysis, design, manufacture and testing. The needs analysis was based on many students, especially the BPRS ERA-FM UNJ crew who were late coming to class while in the secretariat by making a questionnaire for the need for tools. Designing alarms to match real time with the RTC module, DFPlayer Mp3 and speakers to make sounds, and RFID as a security and student lecture hours that have been inputted. Separate testing to test the results of sound, time, security, and test the entire program of lecture reminder alarms.

The results showed how the making of prototype alarm lecture reminder alarm time based on arduino mega microcontroller. And trials of each module, starting with DFPlayer Mp3, RTC, RFID, door lock solenoid, relay, and the entire lecture reminder alarm system.

Keywords : BPRS ERA-FM secretariat UNJ, Lecture Time Reminder Alarm, Control System, Arduino Mega, RFID Module, RTC Module, Mp3DFPlayer Module, alarm time reminder lecture based on arduino mega microcontroller
\end{abstract}

\begin{abstract}
Abstrak
Tujuan dari penelitian ini adalah membuat alarm publik untuk mengurangi angka keterlambatan mahasiswa aktif untuk masuk kelas perkuliahan saat berada di dalam sekretariat BPRS ERA-FM UNJ dengan menyebutkan nama mahasiswa secara personal yang memiliki waktu perkuliahan, pengingat disaat mahasiswa lupa saat sedang siaran, berbincang ataupun membuat tugas lainnya, karena BPRS ERA-FM UNJ adalah unit kegiatan mahasiswa yang setiap hari memiliki kesibukan yaitu siaran itu sendiri. Serta keamanan sekretariat dengan menggunakan kartu sebagai pengganti kunci manual untuk mengurangi kehilangan barang barang sekretariat. Arduino mega sebagai mikrokontroller utamanya mengendalikan sistem alarm dan keamanan sekretariat. Alat ini menggunakan sumber listrik dari PLN.

Penelitian ini menggunakan metode ADDIE (analysis, design, development, implementation, evaluation) yang meliputi analisis kebutuhan, perancangan, pembuatan dan pengujian. Analisis kebutuhan didasarkan oleh banyak mahasiswa khususnya crew BPRS ERA-FM UNJ yang terlambat datang jam perkuliahan saat berada di dalam sekretariat dengan membuat kuisioner. Merancang alarm agar sesuai dengan waktu nyata dengan modul RTC, Mp3 DFPlayer dan speaker untuk mengeluarkan suara, dan RFID sebagai keamanan serta jam kuliah mahasiswa yang sudah di input. Pengujian secara terpisah untuk mengetes hasil suara, waktu, keamanan, dan menguji keseluruhan program alarm pengingat waktu kuliah.

Hasil penelitian rancang bangun prototipe alarm pengingat waktu kuliah berbasis mikrokontroller arduino mega menunjukkan bahwa RTC membaca hari dan jam waktu kuliah, dengan perbedaan waktu asli dan program berbeda 5 detik dikarenakan uploading program.

Kesimpulan dari penelitian ini adalah crew BPRS ERAFM-UNJ membutuhkan alat ini sebagai pengingat waktu. Kata kunci : sekretariat BPRS ERA-FM UNJ, Alarm Pengingat Waktu Kuliah, Sistem Kendali, Arduino Mega, Modul RFID, Modul RTC, Modul Mp3DFPlayer, alarm pengingat waktu kuliah berbasis mikrokontroller arduino mega.
\end{abstract}

\section{PENDAHULUAN}

Menurut H. Naibaho dan F. Adi dalam jurnal yang berjudul Pengaruh Lingkungan Kampus Terhadap Motivasi Belajar Mahasiswa (2012), lingkungan kampus adalah lingkungan dimana mahasiswa menjalani proses belajar dan melakukan aktivitas. Lingkungan kampus yang kondusif dapat mempengaruhi prestasi belajar mahasiswa. Dalam memenuhi kegiatan di 
kampus banyak sekali mahasiswa yang mengikuti organisasi.

Organisasi adalah bagian yang tak terlepaskan dari bagian mahasiswa dalam proses belajar dan menjadi lebih aktif karena, Ayu Luhuan (2014) "agent of change adalah sekelompok orang yang mendapat perhatian dan harapan masyarakat untuk dapat memimpin dan menjalan sistem sosial".

Namun dalam mengikuti kegiatan organisasi, tentu saja memiliki hal positif dan negatif, mahasiswa yang berorganisasi banyak sekali waktu yang dibutuhkan untuk mengerjakan tugas di luar akademik. Organisasi non akademik seperti ORMAWA dan OPMAWA contohnya, memerlukan waktu yang lebih untuk mengoptimalkan setiap tugas yang menjadi tanggung jawabnya di dalam dunia organisasi dan perkuliahan, karena dalam dunia organisasi pasti memiliki tugas pokok kerja tahunan untuk di kerjakan dalam satu periode atau satu tahun kepengurusan.

Seperti mahasiswa di Universitas Negeri Jakarta yang aktif dalam organisasi kampus terutama di unit kegiatan mahasiswa BPRS ERAFM-UNJ yang setiap hari mengisi siaran On Air yang dimulai pada pukul 08.00 WIB sampai dengan pukul 19.00 WIB dari mata acara morning soul sampai PUPUS (pulang ngampus). Pada setiap program mata acara, terdapat produser yang mengontrol penyiar, teknikal menyiapkan alat siar, music director membuat playlist. Dikarenakan kegiatan tersebut, mengakibatkan crew BPRS ERAFM-UNJ melalaikan waktu kuliah, makan, dan lain sebagainya. Banyak juga mahasiswa yang menjadikan gedung $\mathrm{G}$ sebagai rumah kedua bagi mereka, sehingga banyak dari mereka merasa nyaman untuk berlama-lama karena banyak berinteraksi dengan mahasiswa lain.

Selama ini mahasiswa aktif hanya bergantung kepada grup kelas masing masing untuk menanyakan waktu kuliahnya, ataupun mempunyai alarm pribadi masing-masing di handphone. Alarm saat ini hanya mengeluarkan suara musik seperti 'bip bip' dan lain sebagainya sesuai bawaan handphone untuk mengingatkan mahasiswa tersebut. Dan untuk mengingatkan mahasiswa terhadap waktu terutama di dalam sekretariat BPRS ERAFM-UNJ baik secara personal atau secara universal dibutuhkan alarm pengingat waktu kuliah untuk mengingatkan masing masing mahasiwa saat masuk kelas. Setiap harinya banyak mahasiswa lupa untuk masuk kelas karena fokus dalam kegiatan sehari hari di dalam sekretariat BPRS ERAFM- UNJ.

Salah satu penyebab aktifnya mahasiswa dalam organisasi BPRS ERAFM- UNJ adalah tidak mengetahui adanya tugas dan lupa untuk bertanya sehingga tugas yang seharusnya dikerjakan di dalam kelas tidak dikerjekan, karena mahasiswa tersebut lupa masuk waktu kelas dan lebih memilih menghabiskan waktu di sekretariat, sehingga mahasiswa tersebut mengalami penundaan waktu kuliah. Penggunaan alarm pada unit kegiatan mahasiswa BPRS ERAFM-UNJ diharapkan dapat menurunkan jumlah mahasiswa yang lupa masuk kelas, sehingga mahasiswa tersebut dapat seimbang antara akademik dan non akademik.

Masalah lain yang muncul adalah keamanan di sekrtariat, karena beberapa saat yang lalu pernah terjadi kehilangan alat elektonik, seperti kamera, printer, dan beberapa barang lainnya. Masalah pada keamanan yaitu kunci pintu konvensional biasanya hanya satu dan disimpan di tempat tertentu, namun hal tersebut tidak aman karena orang lain selain anggota BPRS ERAFM-UNJ dapat mengetahui keberadaan kunci tersebut. Penambahan keamanan di dalam program prototipe pengingat waktu kuliah menjadi penting dilihat dari masalah keamanan yang terjadi di sekretariat BPRS ERAFM-UNJ untuk mencegah terjadinya kehilangan barang dikemudian hari.

Prototipe pengingat waktu kuliah yang akan digunakan dalam penelitian ini adalah berbasis arduino Mega sebagai alarm publik yang ditujukan untuk setiap anggota (personal) di dalam sekretariat. Alarm publik dan anggota lain mengingatkan secara lisan jika anggota tertidur untuk memperkuat dorongan tidak telat masuk kelas perkuliahan. Hal ini merupakan salah satu cara yang ingin diterapkan untuk mengatasi mahasiswa masuk kelas perkuliahan dengan tepat waktu. 


\section{METODE PENELETIAN}

Penelitian ini bertujuan untuk membuat prototipe alarm pengingat waktu kuliah bebasis mikrokontroller ini adalah sebagai media baru dalam alarm publik bagi mahasiswa aktif organisasi. Prosedur penelitian ini mengadaptasi model pengembangan ADDIE yang terdiri dari lima tahapan yang meliputi analisis (analysis), desain (design), pengembangan (development), implementasi (implementation) dan evaluasi (evaluation) (Sugiyono, 2015: 200). Adapun langkah penelitian pengembangan ADDIE dalam penelitian ini jika disajikan dalam bentuk bagan adalah sebagai berikut:

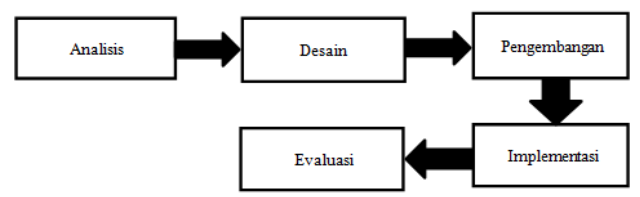

\section{Gambar 3.1. Langkah-langkah model} pengembangan ADDIE

Pada tahap analisis kebutuhan ini peneliti melakukan penelitian pendahuluan yang dilakukan kepada 28 mahasiswa Universitas Negeri Jakarta yang menjadi crew BPRS ERA FM-UNJ apakah membutuhkan alarm publik untuk mengingatkan mahasiswa masuk kuliah akademik, hasil dari penelitian yang di ambil berupa quisioner mahasiswa sekaligus crew BPRS ERA FM- UNJ membutuhkan inovasi baru untuk membantu mereka mengingatkan masuk kelas.

Sebelum memulai membuat kuisioner penulis menanyakan terlebih dahulu masalah yang di hadapi mahasiswa dan sehingga mereka telat atau lupa untuk menuju ke ruang kelas masing-masing. Dari beberapa pertanyaan yang penulis berikan kepada mahasiswa, mereka menyatakan bahwa mereka telat karena beberapa seperti lupa saat sedang siaran on air radio, mengerjakan tugas akademik dan non akademik, dan tertidur sehingga tidak ada yang mengingatkan mereka untuk masuk kuliah.

Pada tahap ini desain media yang dikembangkan digambarkan dalam tahap-tahap berikut:

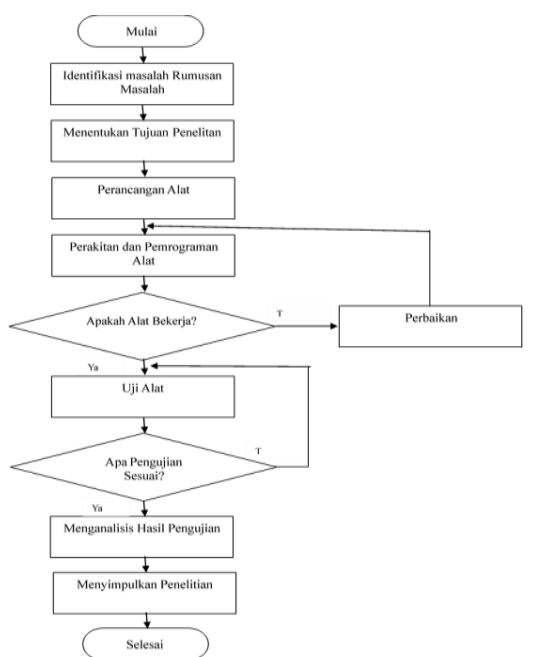

Gambar 3.2. Flowchart Penelitian

Desain produk yang telah disusun, dikembangkan berdasarkan tahap- tahap berikut:

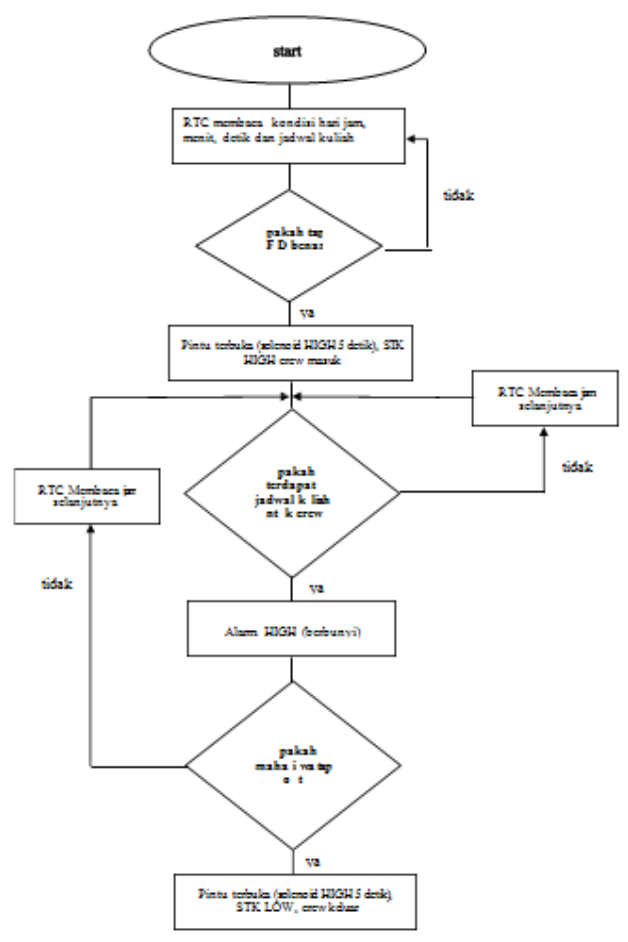

Gambar 3.3. flowchart kerja alat 
HASIL DAN PEMBAHASAN

Hasil Penerapan Sistem Mp3 Dfplayer

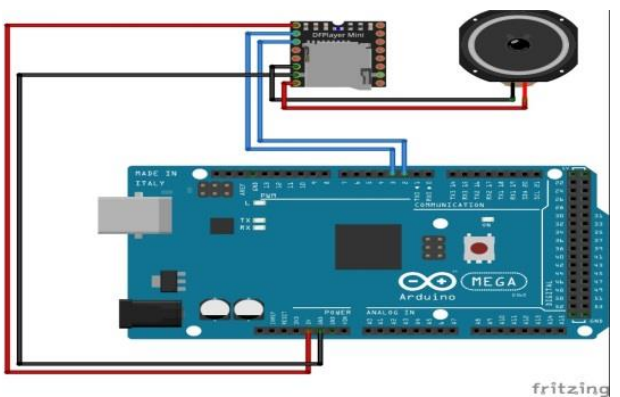

Gambar 4.1. Sistem Mp3 dfplayer

Tabel 4.1. Uji Coba Mp3 dfplayer Suara

\begin{tabular}{llllll}
\hline & & & \multicolumn{3}{c}{ Suara } \\
& No & Tombol & Alarm & Kurang & $\begin{array}{l}\text { Tidak } \\
\text { Jelas }\end{array}$ \\
\hline 1 & 1 & Jlarm 1 & Jelas & - & - \\
2 & 2 & Alarm 2 & Jelas & - & - \\
3 & 3 & Alarm 3 & Jelas & - & - \\
4 & 4 & Alarm 4 & Jelas & - & - \\
5 & 5 & Alarm 5 & - & Kurang & - \\
6 & 3 & Alarm 3 & Jelas & - & - \\
7 & 2 & Alarm 2 & Jelas & -
\end{tabular}

$\begin{array}{llllll}8 & 5 & \text { Alarm } 5 & - & \begin{array}{l}\text { Kurang } \\ \text { Jelas }\end{array} & \text { - } \\ 9 & 1 & \text { Alarm } 1 & \text { Jelas } & - & - \\ 10 & 4 & \text { Alarm } 4 & \text { Jelas } & - & -\end{array}$

Dari tabel 4.1 dapat dilihat bahwa dalam program mp3 dfplayer dapat memainkan alarm sesuai dengan yang diinginkan, baik berurutan ataupun secara acak. saat ingin mengaktifkan alarm satu maka menekan tombol satu, dan seterusnya. dapat di mainkan sesuai apa yang diinginkan penulis. Dan setiap durasi alarm sudah sesuai setelah dilakukan uji coba serta kualitas suara yang di keluarkan sudah cukup jelas sesuai dengan yang diinginkan.

\section{Penerapan Sistem Solenoid dan RFID}

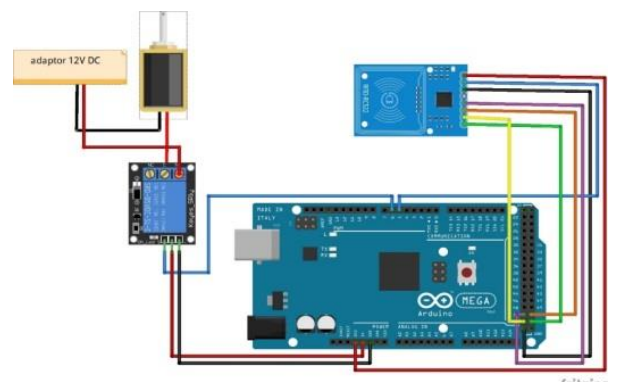

Gambar 4.2 Sistem RFID dan Solenoid Tabel 4.2. Uji Coba RFID

\begin{tabular}{|c|c|c|c|c|}
\hline \multicolumn{5}{|c|}{ ReaderRFID } \\
\hline No & TagRFID & $\begin{array}{c}\text { kondisi } \\
\text { awal }\end{array}$ & pengujian & serial monitor \\
\hline 1 & $\begin{array}{c}6024 \mathrm{CD} \\
0 \mathrm{E}\end{array}$ & Off & On & $\begin{array}{l}6024 \text { CD 0E } \\
\text { "MASUK" }\end{array}$ \\
\hline 2 & $\begin{array}{c}2047 \mathrm{DA} \\
0 \mathrm{E}\end{array}$ & Off & On & $\begin{array}{l}2047 \text { DA 0E } \\
\text { "MASUK" }\end{array}$ \\
\hline 3 & $\begin{array}{c}\text { D0 } 28 \mathrm{DA} \\
\text { 0E }\end{array}$ & Off & On & $\begin{array}{l}\text { D0 } 28 \text { DA 0E } \\
\text { "MASUK" }\end{array}$ \\
\hline 4 & $6051 \mathrm{D} 90 \mathrm{E}$ & Off & On & $\begin{array}{l}6051 \text { D9 0E } \\
\text { "MASUK" }\end{array}$ \\
\hline 5 & $\begin{array}{c}40 \text { 4D D9 } \\
\text { 0E }\end{array}$ & Off & On & $\begin{array}{l}40 \text { 4D D9 0E } \\
\text { "MASUK" }\end{array}$ \\
\hline
\end{tabular}




\begin{tabular}{|c|c|c|c|c|}
\hline 6 & B9 A0 5801 & Off & On & $\begin{array}{l}\text { B9 A0 } 5801 \\
\text { "MASUK" }\end{array}$ \\
\hline 7 & E0 54 D9 0E & Off & On & $\begin{array}{l}\text { E0 } 54 \text { D9 0E } \\
\text { "MASUK" }\end{array}$ \\
\hline 8 & $\begin{array}{c}\text { E0 } 46 \text { DA } \\
0 \mathrm{E}\end{array}$ & Off & On & $\begin{array}{l}\text { E0 } 46 \text { DA 0E } \\
\text { "MASUK" }\end{array}$ \\
\hline 9 & $\begin{array}{c}8036 \mathrm{DB} \\
0 \mathrm{E}\end{array}$ & Off & On & $\begin{array}{l}8036 \text { DB 0E } \\
\text { "MASUK" }\end{array}$ \\
\hline 10 & $807 \mathrm{E} \mathrm{C4} 0 \mathrm{E}$ & Off & On & $\begin{array}{l}80 \text { 7E C4 OE } \\
\text { "MASUK" }\end{array}$ \\
\hline 11 & $5052 \mathrm{D} 90 \mathrm{E}$ & Off & On & $\begin{array}{l}5052 \text { D9 0E } \\
\text { "MASUK" }\end{array}$ \\
\hline 12 & $\begin{array}{c}89 \text { 1C E5 } \\
\text { A9 }\end{array}$ & Off & On & $\begin{array}{l}89 \text { 1C E5 A9 } \\
\text { "MASUK" }\end{array}$ \\
\hline 13 & $\begin{array}{c}3037 \mathrm{DB} \\
0 \mathrm{E}\end{array}$ & Off & On & $\begin{array}{l}3037 \text { DB 0E } \\
\text { "MASUK" }\end{array}$ \\
\hline 14 & $\begin{array}{c}5037 \mathrm{DB} \\
0 \mathrm{E}\end{array}$ & Off & On & $\begin{array}{l}5037 \text { DB 0E } \\
\text { "MASUK" }\end{array}$ \\
\hline 15 & 71 5C F4 08 & Off & On & $\begin{array}{l}71 \text { 5C F4 } 08 \\
\text { "MASUK" }\end{array}$ \\
\hline 16 & $\begin{array}{c}5037 \mathrm{DB} \\
0 \mathrm{E}\end{array}$ & Off & On & $5037 \mathrm{DB} 0 \mathrm{E}$ \\
\hline 17 & $\begin{array}{c}04 \text { 2E 5D } \\
2 \mathrm{~A} \mathrm{~F} 8\end{array}$ & Off & On & 04 2E 5D 2A F8 \\
\hline 18 & $\begin{array}{c}6024 \mathrm{CD} \\
0 \mathrm{E}\end{array}$ & Off & On & $6024 \mathrm{CD} 0 \mathrm{E}$ \\
\hline 19 & C987 8A 05 & Off & On & C987 8A 05 \\
\hline 20 & $\begin{array}{c}04440 A \\
\text { CA } 38\end{array}$ & Off & On & 0444 0A CA 38 \\
\hline
\end{tabular}

Dapat dilihat dari tabel, bahwa tag yang telah di masukkan dan berhasil saat dilihat pada serial monitor tertulis nomer tag "MASUK", dan yang tidak dimasukkan nomer tag akan tertulis hanya nomer tag tersebut sesuai dengan input yang dimasukkan kedalam program.

Setelah uji coba program RFID selanjutnya penulis melakukan uji coba solenoid, berikut adalah hasil dari tabel uji coba program solenoid bekerja sesuai dengan tag RFID yang sudah di input dalam program. Dilihat dari hasil yang di inginkan adalah "nomer tag, masuk, open" dam jika nomer tag RFID tidak sesuai dengan yang dimasukan ke program maka dalam serial monitor hanya akan terbaca nomer tag RFID saja.

Program dari solenoid dapat bekerja dengan baik sesuai dengan yang diinginkan penulis, yaitu dapat membaca limabelas tag RFID dan solenoid terbuka dengan kondisi awal solenoid low atau terkunci dan akan high atau terbuka sesuai dengan input tag RFID. Berikut dokumentasi dari hasil uji coba solenoid 


\section{Penerapan Sistem RTC}

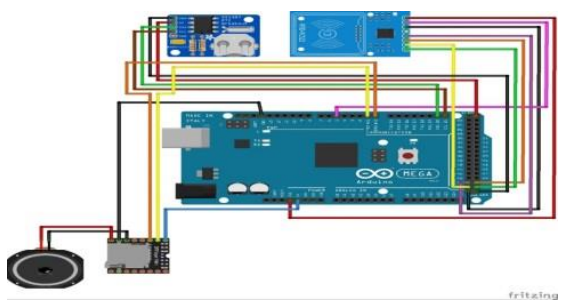

Gambar 4.4 Sistem RTC Real Time Clock

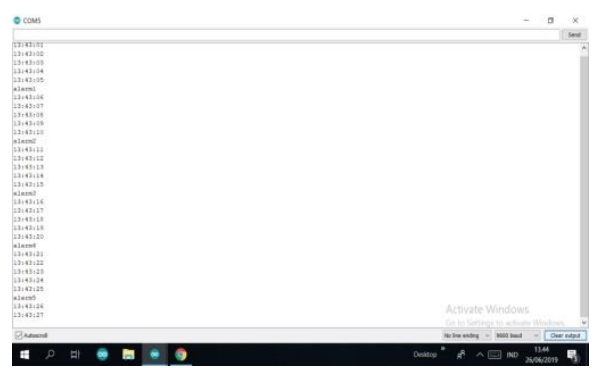

Gambar 4.5 hasil RTC

\section{Penerapan Sistem Stopkontak}

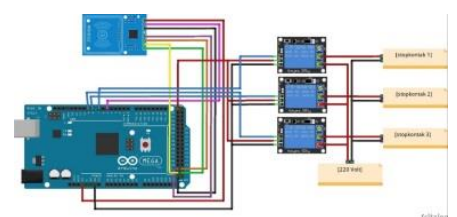

\section{Gambar 4.6 Sistem Relay}

Kondisi awal adalah stopkontak dalam kondisi off dan reader RFID dalam kondisi standby karena belum ada tag RFID yang di oprasikan atau ditempelkan.

Hasil uji coba kondisi masuk reader akan aktif yaitu saat setiap tag mulai di oprasikan atau di tempel sekali baik secara berurutan atau secara acak. Penulis membuat kelompok untuk setiap stopkontak, tag satu sampai lima berada dalam kelompok satu untuk stopkontak 1, tag enam sepuluh berada dalam kelompok dua atau stopkontak 2, dan tag sebelas sampai limabelas berada di kelompok tiga atau stopkontak 3 . Dapat dipastikan untuk uji coba yang dilakukan penulis sudah sesuai yang diinginkan.

Kondisi kedua saat setiap tag di oprasikan atau di tempelkan ke reader maka kondisi keluar, dan kondisi ini stopkontak 1 sampai stopkontak 3 akan mati atau off saat semua tag telah di oprasikan atau di tempelkan ke reader.

\section{Penerapan Alarm Pengingat Waktu Kuliah}

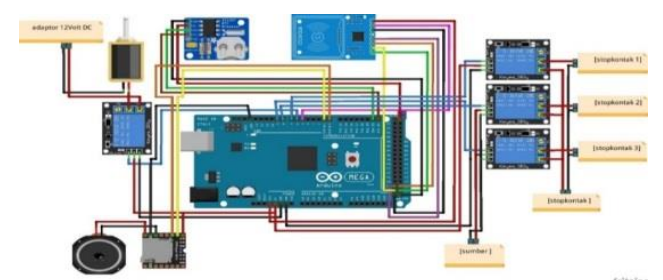

\section{Gambar 4.7 Sistem Alarm Pengingat Waktu Kuliah}

Alarm bekerja sesuai yang telah di program di dalam dengan tag RFID, sesuai dengan jam kuliah mahasiswa dan stopkontak berjalan sesuai dengan kelompok tag RFID. Penulis melakukan uji coba dan hasil pengujian yang telah dilakukan dari hari senin mulai dari jam 07:00 sampai 14:50 WIB, hasil uji coba yang dilakukan dengan melihat alarm berbunyi lima belas menit sebelum jam matakuliah pertama, kedua, atau ketiga dimulai. Tabel dibawah adalah hasil dari pengujian selama satu hari.

1. Hasil pengujian pada Pukul 07:00 yang di lakukan pada tabel 4.8. adalah saat crew masuk kedalam sekretariat BPRS ERAFMUNJ. Dari hasil pengujian RFID high saat tag RFID di tap ke reader RFID, solenoid HIGH selama 5 detik, dan stopkontak high.

2. Pengujian yang pada Pukul 07:45 saat semua crew berada di dalam BPRS ERAFM-UNJ. Alarm berbunyi atau high, menyebutkan nama crew yang memiliki waktu perkuliahan di pukul 08:00. Sesuai dengan yang diinginkan yaitu 15 menit sebelum jam perkuliahan dimulai alarm berbunyi.

3. Pengujian yang dilakukan pada 07:46-07:50 saat crew keluar dari sekretariat BPRS ERAFM-UNJ. RFID high saat tag RFID di tap ke reader RFID, solenoid high atau pintu terbuka selama 5 detik, dan stopkontak low.

4. Hasil pengujian yang di lakukan pada pukul 09.10-09.13 adalah saat crew masuk kedalam sekretariat BPRS ERAFM-UNJ. Dari hasil pengujian RFID high saat tag RFID di tap ke reader RFID, solenoid HIGH selama 5 detik, dan stopkontak high.

5. Pengujian yang dilakukan pada pukul 09.45 saat semua crew berada di dalam BPRS ERAFM-UNJ. Alarm berbunyi atau high, menyebutkan nama crew yang memiliki 
waktu perkuliahan di pukul 10:00. Sesuai dengan yang diinginkan yaitu 15 menit sebelum jam perkuliahan dimulai alarm berbunyi.

6. Pengujian yang dilakukan pada pukul 09.4609.49 saat crew keluar dari sekretariat BPRS ERAFM-UNJ. RFID high saat tag RFID di tap ke reader RFID, solenoid high atau pintu terbuka selama 5 detik, dan stopkontak low.

7. Hasil pengujian yang di lakukan pada pukul 12.30-12.33 adalah saat crew masuk kedalam sekretariat BPRS ERAFM-UNJ. Dari hasil pengujian RFID high saat tag RFID di tap ke reader RFID, solenoid HIGH selama 5 detik, dan stopkontak high.

8. Pengujian yang dilakukan pada pukul 12.45 saat semua crew berada di dalam BPRS ERAFM-UNJ. Alarm berbunyi atau high, menyebutkan nama crew yang memiliki waktu perkuliahan di pukul 13:00. Sesuai dengan yang diinginkan yaitu 15 menit sebelum jam perkuliahan dimulai alarm berbunyi.

9. Pengujian yang dilakukan pada pukul 12.4612.50 saat crew keluar dari sekretariat BPRS ERAFM-UNJ. RFID high saat tag RFID di tap ke reader RFID, solenoid high atau pintu terbuka selama 5 detik, dan stopkontak low.

10. Hasil pengujian yang di lakukan pada pukul 14.38-14.41 adalah saat crew masuk kedalam sekretariat BPRS ERAFM-UNJ. Dari hasil pengujian RFID high saat tag RFID di tap ke reader RFID, solenoid HIGH selama 5 detik, dan stopkontak high.

11. Pengujian yang dilakukan pada pukul 14.45 saat semua crew berada di dalam BPRS ERAFM-UNJ. Alarm berbunyi atau high, menyebutkan nama crew yang memiliki waktu perkuliahan di pukul 13:00. Sesuai dengan yang diinginkan yaitu 15 menit sebelum jam perkuliahan dimulai alarm berbunyi.

12. Pengujian yang dilakukan pada pukul 14.4614.50 saat crew keluar dari sekretariat BPRS ERAFM-UNJ. RFID high saat tag RFID di tap ke reader RFID, solenoid high atau pintu terbuka selama 5 detik, dan stopkontak low.

\section{KESIMPULAN DAN SARAN Kesimpulan}

Pada akhir perancangan dan pembuatan Rancang Bangun Prototipe Alarm Pengingat Waktu Kuliah Berbasis Mikrokontroller Arduino Mega Di Ruang Unit Kegiatan Mahasiswa BPRS ERAFM-UNJ, maka dapat disimpulkan bahwa, pada pembuatan alat dalam penelitian ini menggunakan modul selenoid dan RFID sebagai kunci dan akses anggota organisasi yang masuk/keluar ruangan. Selain itu modul RFID juga sebagai counter untuk menentukan anggota berada di dalam/luar ruangan, kemudian menggunakan modul RTC sebagai input untuk mengaktifkan pengaturan waktu, serta melakukan penyimpanan data pada program yang dijalankan oleh RTC. Mikrokontroler yang dipakai adalah Arduino Mega 2560 dan dijalankan menggunakan Software Arduino IDE. Selanjutnya, pada rancang bangun yang dibuat, terjadi perbedaan waktu sekitar 5 detik antara waktu di RTC dengan waktu realtime karena lamanya waktu pengupload an program. Pada protipe ini, alarm akan berbunyi 15 menit sebelum jadwal perkuliahan anggota dimulai.

\section{Saran}

Dari hasil penilitian dan uji coba yang telah dilakukan, masih terdapat kekurangan. Agar penelitian lebih sempurna sebaiknya ada hal yang harus diperhatikan yaitu :

1. Penggunaan tipe modul RFID yang kurang akurat dalam pengambilan data anggota, sehingga pada proses tab kartu RFID memerlukan beberapa kali proses tab agar kartu RFID terdeteksi.

2. Perubahan jadwal perkuliahan seharusnya bisa dilakukan secara perorangan melalui gadget masing-masing anggota.

3. Untuk akses masuk atau keluar dan alarm berbunyi seharusnya di tampilkan pada LCD disimpan ke dalam database.

\section{DAFTAR PUSTAKA}

Akintola, K. G., \& Boyinbode, O.K. 2011. The Place of Emerging RFID

Technology in National Security and Development. International Journal Of Smart Home, Vol. 5, No. 2

Astono, R. 2006. Implementasi Dan Perancangan Kunci Pintu Hotel Dengan 
Radio Frequency Identification (RFID). Skripsi. Program Studi Pendidikan Teknik Elektro Universitas Negeri Semarang. Semarang

Anonim, "Mengenal Arduino Mega 2560," 2018. [Online].

Available:http://ecadiocom/belajar-danmengenal-arduino-mega

Aptaji, “Arduino Sebagai RTC,” 2015. [Online]. Available:

http://saptaji.com/2015/06/24/arduinosebagai-rtc-real-time-clock/.

Ayu Luhuan 2014 https://www.indonesiastudents.com/peng ertian-agent-of-change-menurut-paraahli/\#Sofyan_2014. Diakses pada tanggal 2 agustus 2019

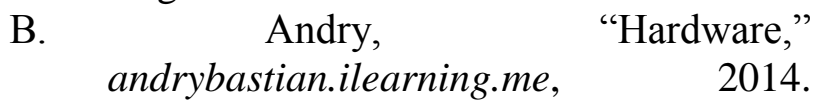
[Online].

Available: http://andrybastian.ilearning.me/wpcontent/uploads/sites/176/2014/10

Dang, H. T. 2013. Investigate And Design A 13.56MHz RFID Reader. Tesis. School Of Electrical Engineering Ho Chi Minh City International University (Vietnam National University). Ho Chi Minh

Denoia, L. A. dan A. L. Olsen. 2009. RFID and Application Security. Journal Of Research and Practice in Information Technology41(3): 209-221.

D. Kho, "Pengertian Solenoida (Solenoid) dan jenis-jenis Solenoida." [Online]. Available:https://teknikelektronika.com/p engertian-solenoida-cara-kerja-jenissolenoid/

Dickson Kho. Pengertian Speaker dan Prinsip kerjanya, [Online]. Available: (https://teknikelektronika.com/fungsipengertian-speaker-prinsip-kerjaspeaker/. [8 Agustus 2019]

E. Novitasari, "Penyeleksi Bola Pingpong Berdasarkan Warna," 2017. [Online]. Available: https://belajarmikrokontroler2017.com [8 Agustus 2019 Eka Budhy Prasetya, "Pemantau Kebocoran Ac Menggunakan Sensor Y183 Dan Lm35dz Berbasis Mikrokontroler Arduino Melalui Webserver," J. Elektum Vol. 14 No. 2
Gabriel, A. K. Dan O. K. Boyinbode. 2011. The Place of Emerging RFID Technology in National Security and Development. International Journal of Smart Home 5(2): 37-43.

Hari, S. (2017). Panduan Praktis Belajar Arduino untuk Pemula. Malang

http://www.alldatasheet.com diakses pada tanggal 10 Mei 2019

H. Naibaho, F. Adi, . V., and . S., "Pengaruh Lingkungan Kampus Terhadap

Motivasi Belajar Mahasiswa (Studi Kasus Universitas Pelita Harapan Surabaya)," J. Manaj. Pemasar., vol. 5, no. 1, Mar. 2012.

Hakim, "Pengertian Prototipe," Scribd, 2011. [Online].

Available: http://scribd.com/doc/58298607/Pengertia n-Prototype.

Jurnal sandro lumban tobing [Online].

https://www.scribd.com/document/250979219/ Solenoid-Door-Lock-Jurnal [8 Agustus 2019]

J. Sitepu, "Modul RTC DS3231," 2018. [Online].

Available:https://mikroavr.com/jam-digitalarduino-ds3231/. [8 Agustus 2019]

Kadir, A. (2013). Panduan Praktis Mempelajari Aplikasi Mikrokontroler. Yogyakarta: Andi Offset.

Nwaji, O. G., N. C. Onyebuchi, dan Dr. O. F. Kelechi. 2013. Automatic Door Unit Radio Frequency Identification (RFID) Based Attedance System. International Journal Science and Emerging Technologies 5(6): 200-211.

N. Jaya, "Modul Relay." [Online]. https://teknikelektronika.com/pengertian

relay fungsi-relay/. [8 Agustus 2019] Pelton., G. E. (1993). Voice Processing. New York: McGraw-Hill.

Riza, M. 2014. Perancangan Keamanan Pintu Otomatis Berbasis RFID (Radio Frekuensi Identification). Skripsi. Program Studi Teknik Informatika Universitas U'budiyah Indonesia. Aceh.

Sugiyono.(2011). Metode Penelitian Pendidikan Kuantitatif Kualitatif dan $R \& D$. Bandung: Alfabeta 